\title{
Closed suction drain outputs at 12 and 24 hours after primary three- piece inflatable penile prosthesis surgery
}

\author{
Michel Apoj ${ }^{1} \cdot$ Dayron Rodriguez $^{2} \cdot$ Philip Barbosa $^{3} \cdot$ Shu Pan $^{2} \cdot$ Archana Rajender $^{2} \cdot$ Mark Biebel $^{2} \cdot$ Martin Gross $^{4}$. \\ Ricardo Munarriz ${ }^{2}$
}

Received: 22 January 2019 / Revised: 24 February 2019 / Accepted: 4 March 2019 / Published online: 18 March 2019

(c) Springer Nature Limited 2019

\begin{abstract}
This is a single-institution retrospective study of closed suction drain outputs in primary three-piece IPP cases performed between 2014 and 2017 by a single surgeon. The aim was to investigate the impact of closed suction drains (CSD) during penile prosthesis placement. One hundred and sixty-nine patients underwent intraoperative placement of a closed suction drain. Drain outputs were measured at 12 and $24 \mathrm{~h}$, and postoperative complications were documented. There were no hematomas or infections observed within the patient cohort. The drain output decreased significantly between the first and subsequent $12 \mathrm{~h}$ period. Surgical time was associated with statistically significant increases in CSD output at 12 and $24 \mathrm{~h}$ with a near linear relationship between surgical times and CSD at 12 and $24 \mathrm{~h}$. Penile prosthesis placement in patients on aspirin did not affect the CSD output volume. Closed suction drains should be considered in all patients undergoing placement of inflatable penile prosthesis, particularly in those cases with longer operative time.
\end{abstract}

\section{Introduction}

Inflatable penile prosthesis (IPP) placement is an effective and safe treatment option for erectile dysfunction [1]. It is also associated with high satisfaction and recommendation rates of $85 \%$ and $88 \%$, respectively [2, $3]$. Since the development of the IPP in 1973, complications have steadily declined due to numerous surgical innovations. However, hematoma formation after IPP placement remains a common complication, with reported rates ranging from $0.5 \%$ to $3.6 \%[4,5]$. Hematoma formation may be responsible for slower recovery, prolonged postoperative discomfort, delayed pump cycling,

Ricardo Munarriz

munarriz@bu.edu

Boston University School of Medicine, Boston, MA, USA

2 Department of Urology, Boston Medical Center and Boston University School of Medicine, Boston, MA, USA

3 Division of Urology, Beth Israel Deaconess Medical Center and Harvard Medical School, Boston, MA, USA

4 Department of Urology, Dartmouth-Hitchcock Medical Center, Hanover, NH, USA and pump migration, which may require revisional surgery [6].

The use of closed suction drains (CSDs) in the immediate postoperative period should theoretically decrease hematoma formation, but specific data regarding this practice is limited. In addition, some prosthetic surgeons contend that drain usage may increase penile prosthesis infection rates, despite the lack of evidence to support this assertion in literature. The aim of this study was to investigate the impact of closed suction drainage following penile prosthesis placement on hematoma formation and infection rates.

\section{Material and methods}

This is a single-institution IRB approved (H-37856) retrospective study of CSD outputs in primary threepiece IPP insertion cases performed between 2014 and 2017 by a single surgeon. All patients underwent penoscrotal placement of a three-piece IPP made from Coloplast ${ }^{\mathrm{TM}}$, bathed with vancomycin and gentamicin for a hydrophilic coating, using a no touch scrotal technique with small corporotomies (approximately 1 $\mathrm{cm})$. 2-0 Vicryl holding sutures were preplaced at the corporotomies and tied down in a water-tight, horizontal 
mattress after the placement of the implant. In case of a small corporal gap, a 2-0 Vicryl was placed to close the defect. A 10 French Jackson Pratt (JP) CSD was placed in the scrotum drain exiting the groin via a stab incision. A compression dressing of 4-inch Kerlix ${ }^{\mathrm{TM}}$ dressing roll was applied to the penile shaft and scrotum in the standard "mummy wrap fashion" [7]. All devices used were left fully inflated until drain removal on postoperative day 1 . If patients were taking baby aspirin $(81 \mathrm{mg})$ prior to the procedure, regardless of prophylaxis or necessity, they were continued on the aspirin through the procedure. If patients were on other antiplatelet/anticoagulants such as clopidogrel or coumadin, cardiology clearance was obtained and the medication was discontinued 5 days prior to surgery and restarted $48 \mathrm{~h}$ after surgery. Rarely, cardiology requested a heparin bridge. In these cases, heparin was discontinued the night before surgery and restarted the night after the procedure.

The main outcome measures of the study were CSD outputs at 12 and $24 \mathrm{~h}$ postoperatively and the secondary endpoints were 30-day postoperative hematoma formation and penile prosthesis infection. Statistical analyses were performed with JMP Pro Version 14 (SAS Inc., Cary, NC, USA) and SPSS Statistical Package Version 23.0 (SPSS Inc., Chicago, IL, USA).

Correlation between categorical variables was made using the Chi-square test. Analysis of variance (ANOVA) was used to compare means for variables with more than two groups and $t$-tests were used when comparing means for categorical variables with only two groups. A $p$ value less than 0.05 was considered statistically significant. All statistical tests were two-sided.

\section{Results}

A total of 169 IPPs were placed during the study period, of which 166 (98\%) had drain outputs recorded at both 12 and $24 \mathrm{~h}$. No hematoma formation or penile prosthesis infections were observed in the study cohort. In addition, no drain-related postoperative complications such as pain, discomfort, or skin inflammation at the drain exit site were observed. Patient characteristics are summarized in Table 1. The mean $24 \mathrm{~h}$ postoperative drain output was $162.1 \mathrm{~mL}$ (range $8-570 \mathrm{~mL}$ ). The mean JP output rate in the first and second $12 \mathrm{~h}$ postoperative period was 11.0 and $2.5 \mathrm{~mL} / \mathrm{h}$, respectively (Fig. 1).

Univariate logistic regression analysis was used to determine if medical comorbidities were associated with significant increases in CSD output at 12 and $24 \mathrm{~h}$ (Table 2). Peripheral vascular disease was the only comorbidity associated with decreased CSD output at 12 (137 vs 97.9 $\mathrm{mL} ; p=0.0031)$ and $24 \mathrm{~h}(167.1 \mathrm{vs} 128.8 \mathrm{~mL} ; p=0.038)$.
Table 1 Patient characteristics

\begin{tabular}{|c|c|c|c|}
\hline \multirow[t]{2}{*}{ Characteristic } & \multicolumn{2}{|c|}{ Total } & \multirow[t]{2}{*}{$P$ value } \\
\hline & $N$ & $\%$ & \\
\hline Number of patients & 166 & 100.0 & \\
\hline Age & & & $P<0.01$ \\
\hline $23-49$ & 20 & 12.0 & \\
\hline $50-69$ & 123 & 74.1 & \\
\hline $70+$ & 23 & 13.9 & \\
\hline BMI & & & $P<0.01$ \\
\hline$<25$ & 20 & 12.0 & \\
\hline $25-30$ & 62 & 37.3 & \\
\hline$>30$ & 84 & 50.6 & \\
\hline Race/ethnicity & & & $P<0.01$ \\
\hline White/Caucasian & 52 & 31.3 & \\
\hline Black/African American & 50 & 30.1 & \\
\hline Hispanic & 54 & 32.5 & \\
\hline Asian/Other & 9 & 5.4 & \\
\hline HgbA1C & & & $P<0.01$ \\
\hline $0-6.49$ & 55 & 44.7 & \\
\hline $6.5-10$ & 57 & 46.3 & \\
\hline$>10$ & 11 & 8.9 & \\
\hline ASA $81 \mathrm{mg}$ & & & $P<0.01$ \\
\hline No & 101 & 60.8 & \\
\hline Yes & 65 & 39.2 & \\
\hline Anticoagulation & & & $P<0.01$ \\
\hline No & 160 & 96.4 & \\
\hline Yes & 6 & 3.6 & \\
\hline Current smoker & & & $P<0.01$ \\
\hline No & 128 & 77.1 & \\
\hline Yes & 38 & 22.9 & \\
\hline Former smoker & & & $P<0.01$ \\
\hline No & 78 & 47.0 & \\
\hline Yes & 88 & 53.0 & \\
\hline Operative time (min) & & & $P<0.01$ \\
\hline $0-60$ & 69 & 41.6 & \\
\hline $60-90$ & 81 & 48.8 & \\
\hline$>90$ & 16 & 9.6 & \\
\hline Cylinder size (cm) & & & $P<0.01$ \\
\hline $0-18$ & 62 & 37.3 & \\
\hline$>19$ & 104 & 62.7 & \\
\hline Location of reservoir & & & $P<0.01$ \\
\hline Retropubic & 158 & 95.2 & \\
\hline Ectopic & 8 & 4.8 & \\
\hline \multicolumn{4}{|l|}{ Rear tips } \\
\hline No & 25 & 15.1 & \\
\hline Yes & 141 & 84.9 & \\
\hline
\end{tabular}

Other vascular risk factors for ED (aging, tobacco, obesity, dyslipidemia, diabetes, BMI $>25$, etc.) were not associated with a decrease in CSD outputs. Cigarette smoking almost 


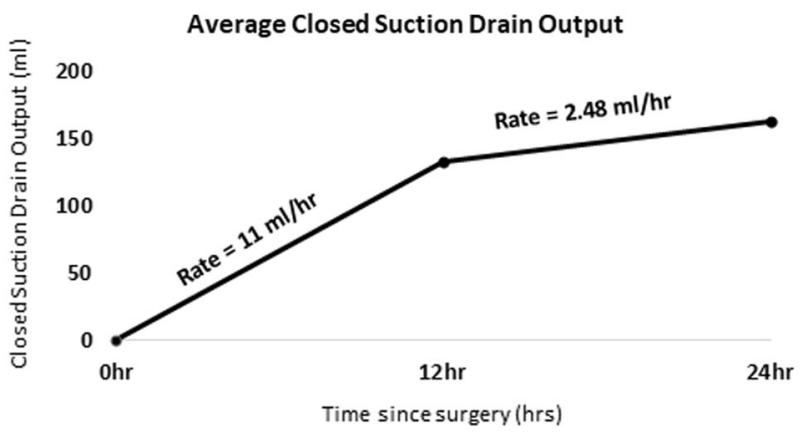

Fig. 1 The mean $24 \mathrm{~h}$ postoperative drain output was $162.1 \mathrm{~mL}$ (range 8-570 mL). The mean JP output rate in the first and second $12 \mathrm{~h}$ postoperative period was 11.0 and $2.5 \mathrm{~mL} / \mathrm{h}$, respectively reached statistical significance $(p=0.082)$. Interestingly, the use of aspirin was not associated ( $p$ 0.827) with increases in CSD outputs at 12 (126 vs $136.4 \mathrm{~mL})$ and $24 \mathrm{~h}$ (160.5 vs $163 \mathrm{~mL}$ ).

Table 3 summarizes the risks factors that may be associated with CSD output. Operative time was the only factor associated with increased closed suction drainage output at $12(p=0.003)$, and with borderline statistical significance at $24 \mathrm{~h}(p=0.05)$. The average CSD outputs were 144.8, 168.7, and $303.1 \mathrm{~mL}$ for operative times of 0-60, 60-90, and greater than $90 \mathrm{~min}$ respectively (Fig. 2). There is almost a linear relationship between surgical times and CSD at 12 and $24 \mathrm{~h}$ (Fig. 2).
Table 2 Closed suction drain output at 12 and $24 \mathrm{~h}$ by medical comorbidities

\begin{tabular}{|c|c|c|c|c|c|c|c|}
\hline \multirow[t]{2}{*}{ Comorbidity } & \multicolumn{2}{|c|}{ Total } & \multirow[t]{2}{*}{$P$ value } & \multirow{2}{*}{$\begin{array}{l}12 \mathrm{~h} \\
\text { Mean (mL) }\end{array}$} & \multirow[t]{2}{*}{$P$ value } & \multirow{2}{*}{$\begin{array}{l}24 \mathrm{~h} \\
\text { Mean (mL) }\end{array}$} & \multirow[t]{2}{*}{$P$ value } \\
\hline & $\mathrm{N}$ & $\%$ & & & & & \\
\hline Hypertension & & & $P<0.01$ & & 0.369 & & 0.622 \\
\hline No & 50 & 30.1 & & 141.2 & & 167.5 & \\
\hline Yes & 116 & 69.9 & & 128.6 & & 159.7 & \\
\hline Hyperlipidemia & & & $P<0.01$ & & 0.090 & & 0.070 \\
\hline No & 54 & 32.5 & & 118.7 & & 143.1 & \\
\hline Yes & 112 & 67.5 & & 139.0 & & 171.2 & \\
\hline Diabetes mellitus & & & $P<0.01$ & & 0.439 & & 0.704 \\
\hline No & 75 & 45.2 & & 137.9 & & 165.12 & \\
\hline Yes & 91 & 54.8 & & 127.9 & & 159.54 & \\
\hline Coronary artery disease & & & $P<0.01$ & & 0.337 & & 0.174 \\
\hline No & 122 & 73.5 & & 128.7 & & 156.1 & \\
\hline Yes & 44 & 26.5 & & 142.7 & & 178.5 & \\
\hline Cerebrovascular event/TIA & & & $P<0.01$ & & 0.100 & & 0.192 \\
\hline No & 155 & 93.4 & & 78.8 & & 159.5 & \\
\hline Yes & 11 & 6.6 & & 125.1 & & 197.7 & \\
\hline Peripheral vascular disease & & & $P<0.01$ & & $0.031^{*}$ & & $0.038 *$ \\
\hline No & 143 & 86.1 & & 137.9 & & 167.1 & \\
\hline Yes & 23 & 13.9 & & 97.9 & & 128.8 & \\
\hline Peyronie's disease & & & $P<0.01$ & & 0.427 & & 0.687 \\
\hline No & 148 & 89.2 & & 130.6 & & 161.0 & \\
\hline Yes & 18 & 10.8 & & 147.1 & & 170.5 & \\
\hline Chronic kidney disease & & & $P<0.01$ & & 0.352 & & 0.394 \\
\hline No & 146 & 88.0 & & 134.6 & & 164.4 & \\
\hline Yes & 20 & 12.0 & & 116.2 & & 145.3 & \\
\hline Hypogonadism & & & $P<0.01$ & & 0.142 & & 0.405 \\
\hline No & 147 & 88.6 & & 129.0 & & 159.9 & \\
\hline Yes & 19 & 11.4 & & 158.7 & & 179.0 & \\
\hline Prostate cancer & & & $P<0.01$ & & 0.547 & & 0.232 \\
\hline No & 120 & 72.3 & & 134.8 & & 167.5 & \\
\hline Yes & 46 & 27.7 & & 126.1 & & 148.0 & \\
\hline Liver disease/cirrhosis & & & $P<0.01$ & & 0.209 & & 0.189 \\
\hline No & 147 & 88.6 & & 135.3 & & 165.5 & \\
\hline Yes & 19 & 11.4 & & 109.8 & & 135.5 & \\
\hline
\end{tabular}


Table 3 Closed suction drain output at 12 and $24 \mathrm{~h}$ by risk factors

\begin{tabular}{|c|c|c|c|c|}
\hline Characteristic & $\begin{array}{l}12 \mathrm{~h} \\
\text { Mean } \\
(\mathrm{mL})\end{array}$ & $P$ value & $\begin{array}{l}24 \mathrm{~h} \\
\text { Mean } \\
(\mathrm{mL})\end{array}$ & $P$ value \\
\hline Overall & 132.4 & & 162.1 & \\
\hline Age & & 0.577 & & 0.577 \\
\hline $23-49$ & 139.1 & & 182.6 & \\
\hline $50-69$ & 128.5 & & 155.1 & \\
\hline $70+$ & 146.9 & & 181.7 & \\
\hline BMI & & 0.942 & & 0.963 \\
\hline$<25$ & 133 & & 160.6 & \\
\hline $25-30$ & 129.5 & & 159.8 & \\
\hline$>30$ & 134.3 & & 164.0 & \\
\hline Race/ethnicity & & 0.470 & & 0.402 \\
\hline White/Caucasian & 133.4 & & 160.8 & \\
\hline $\begin{array}{l}\text { Black/African } \\
\text { American }\end{array}$ & 119.4 & & 154.5 & \\
\hline Hispanic & 141.3 & & 163.7 & \\
\hline Asian/Other & 138.2 & & 205.8 & \\
\hline $\operatorname{HgbA1C}(\%)$ & & 0.539 & & 0.827 \\
\hline $0-6.49$ & 140.2 & & 168.0 & \\
\hline $6.5-10$ & 124.5 & & 157.5 & \\
\hline$>10$ & 120.91 & & 166.8 & \\
\hline ASA $81 \mathrm{mg}$ & & 0.432 & & 0.867 \\
\hline No & 136.4 & & 163.0 & \\
\hline Yes & 126.1 & & 160.5 & \\
\hline Anticoagulation & & 0.656 & & 0.535 \\
\hline No & 132.9 & & 162.9 & \\
\hline Yes & 117.5 & & 138.7 & \\
\hline Current smoker & & 0.284 & & 0.206 \\
\hline No & 136.13 & & 167.1 & \\
\hline Yes & 119.68 & & 145.1 & \\
\hline Former smoker & & 0.333 & & 0.082 \\
\hline No & 139.0 & & 175.5 & \\
\hline Yes & 126.5 & & 150.1 & \\
\hline Operative time (min) & & $0.003^{*}$ & & $0.050 *$ \\
\hline $0-60$ & 110.0 & & 144.8 & \\
\hline $60-90$ & 140.9 & & 168.7 & \\
\hline$>90$ & 181.9 & & 203.1 & \\
\hline Cylinder size $(\mathrm{cm})$ & & 0.516 & & 0.358 \\
\hline $0-18$ & 126.9 & & 153.4 & \\
\hline$>19$ & 135.6 & & 167.2 & \\
\hline Location of reservoir & & 0.369 & & 0.323 \\
\hline Retropubic & 131.06 & & 160.4 & \\
\hline Ectopic & 158.13 & & 194.1 & \\
\hline Rear tips & & 0.926 & & 0.955 \\
\hline No & 133.8 & & 161.1 & \\
\hline Yes & 132.1 & & 162.2 & \\
\hline
\end{tabular}

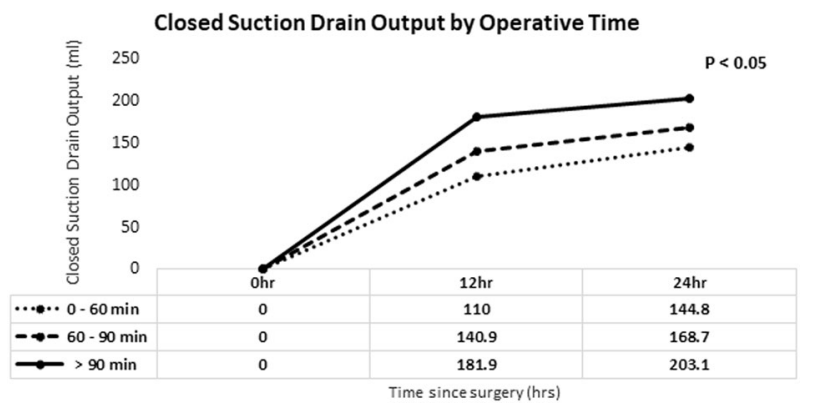

Fig. 2 The average CSD outputs were 144.8, 168.7, and $303.1 \mathrm{~mL}$ for operative times of 0-60, 60-90, and greater than $90 \mathrm{~min}$, respectively. There is almost a linear relationship between surgical times and CSD at 12 and $24 \mathrm{~h}$

\section{Discussion}

Controversy regarding CSD usage stems from the lack of well-designed, prospective, randomized trials evaluating the role of postoperative drain placement during penile prosthesis surgery. Some surgeons cite the lack of compelling evidence and the potential risk of infection as reasons not to place a surgical drain at the time of penile prosthesis surgery. The aim of this study was to investigate the impact of CSD during IPP placement on hematoma formation and infection rates.

This study documents a high CSD output (averaging $132.4 \mathrm{~mL}$ at $12 \mathrm{~h}$ and $162.1 \mathrm{~mL}$ at $24 \mathrm{~h}$ postoperatively) despite the use of established techniques such as small corporotomies, compressive dressing, and postoperative device inflation. Peripheral vascular disease was the only comorbidity associated with decreased CSD output at 12 and $24 \mathrm{~h}$. However, other vascular risk factors (aging, tobacco, obesity, dyslipidemia, diabetes, etc.), which are associated with decreased penile vascular blood flow, were not associated with decreased CSD outputs. Cigarette smoking almost reached statistical significance $(p=0.082)$. Interestingly, the use of aspirin was not associated $(p=$ 0.827) with increases in CSD outputs at 12 and $24 \mathrm{~h}$. The reasons for these findings are unclear and require further investigation.

Hematoma formation after placement of penile prosthesis is a common complication with reported rates between $0.5 \%$ and $3.6 \%[4,5]$. Hematomas may be responsible for slower recovery, prolonged postoperative discomfort, delayed pump cycling, and pump migration, which may result in subsequent lead to revision surgery [6]. We did not have any 30-day hematoma formation in 166 consecutive cases with a combination of small corporotomies, compression dressing, device inflation, and CSD. We strongly believe that these surgical techniques in combination with 
the use of CSD are primary drivers in reducing hematoma formation. Our findings are consistent with literature from other prosthetic surgical fields, which demonstrates that the use of CSD is an effective method to prevent postoperative hematomas [8].

Some prosthetic surgeons contend that the use of CSD may increase penile prosthesis infection rates, even though this hypothesis has not been proven in the urologic literature [9]. This assertion does not reflect the available data, which clearly demonstrates that CSDs do not serve as a nidus of infection and are not associated with increased infection rates $[10,11]$. We had no penile prosthesis infections in our study, in keeping with other studies of CSD [10, 11]. However, this study was neither designed nor powered to detect a difference in infectious outcome following an IPP placement.

To our knowledge, the proper timing of drain removal has not been examined in prosthetic urology. The critical time frame at which drains should be removed has been extensively examined in orthopedics and plastic surgery. Drain removal timing after breast augmentation and total joint arthroplasty has been reported as 12 and $24 \mathrm{~h}$, respectively $[12,13]$. In our study, CSD output significantly decreased from 11.0 to $2.5 \mathrm{~mL} / \mathrm{h}$ during the second $12 \mathrm{~h}$ period. As a result, we advocate limiting the drainage time to a maximum of $24 \mathrm{~h}$ postoperatively. In complex cases, we recommend keeping the drain for $24 \mathrm{~h}$ since our study documents that the average CSD outputs were 144.8, 168.7, and $303.1 \mathrm{~mL}$ for operative times of $0-60,60-90$, and greater than $90 \mathrm{~min}$, respectively, with a near linear relationship between surgical times and CSD at 12 and $24 \mathrm{~h}$ (Fig. 2). However, in uncomplicated cases or when surgery is performed as an outpatient procedure, it may be acceptable to remove the drain after $12 \mathrm{~h}$ as the bulk of the effluent may have already been evacuated.

Limitations of this study include the retrospective nature and the lack of statistical power to definitively demonstrate the association between CSD use and IPP infection rates. However, we strongly believe that our study is consistent with the body of literature documenting the efficacy of CSD in reducing hematomas without an increase in penile prosthesis infection. Prospective randomized trials are needed to confirm our work.

\section{Conclusions}

Our study and those from other prosthetic fields (e.g. orthopedics and plastic surgery) demonstrate that the use of CSD results in fewer postoperative hematomas without increasing infection rates. Penile prosthesis placement in patients on aspirin did not affect the CSD output volume. CSDs should be considered in all patients undergoing IPP placement, particularly in complex cases with lengthy operative times. A prospective randomized study is needed to definitively demonstrate that the use of CSD is not associated with increased infectious complications and may in fact promote convalescence.

\section{Compliance with ethical standards}

Conflict of interest Dr. Munarriz and Dr. Gross both work as consultants to Coloplast.

Publisher's note: Springer Nature remains neutral with regard to jurisdictional claims in published maps and institutional affiliations.

\section{References}

1. Palma-Zamora I, Sood A, Dabaja AA. 30-day adverse event rates following penile prosthesis surgery: an American College of Surgeons National Surgical Quality Improvement Program based evaluation. Transl Androl Urol. 2017;6:S767-S73.

2. Carson CC, Mulcahy JJ, Govier FE. Efficacy, safety and patient satisfaction outcomes of the AMS 700CX inflatable penile prosthesis: results of a long-term multicenter study. AMS 700CX Study Group. J Urol. 2000;164:376-80.

3. Ji YS, Ko YH, Song PH, Moon KH. Long-term survival and patient satisfaction with inflatable penile prosthesis for the treatment of erectile dysfunction. Korean J Urol. 2015;56:461-5.

4. Garber BB, Bickell M. Delayed postoperative hematoma formation after inflatable penile prosthesis implantation. J Sex Med. 2015;12:265-9.

5. Wilson S, Cleves M, Delk JI. Hematoma formation following penile prosthesis implantation: to drain or not to drain. J Urol. 1996;5:155.

6. Perito, P.E., Minimally invasive infrapubic inflatable penile implant. J Sex Med, 2008. 5(1): p. 27-30.

7. Henry GD. The Henry mummy wrap and the Henry finger sweep surgical techniques. J Sex Med. 2009;6:619-22.

8. Scherzer ND, Dick B, Gabrielson AT, Alzweri LM, Hellstrom WJG. Penile prosthesis complications: planning, prevention, and decision making. Sex Med Rev. 2018.

9. Rojas-Cruz C, Sarquella J, Vazquez A. Drain cultures in penile prosthesis implants. J Urol. 2009;181:448.

10. Felippe WA, Werneck GL, Santoro-Lopes G. Surgical site infection among women discharged with a drain in situ after breast cancer surgery. World J Surg. 2007;31:2293-9. discussion 300-1

11. Vilar-Compte D, Mohar A, Sandoval S, de la Rosa M, Gordillo P, Volkow P. Surgical site infections at the National Cancer Institute in Mexico: a case-control study. Am J Infect Control. 2000;28:14-20.

12. Drinkwater CJ, Neil MJ. Optimal timing of wound drain removal following total joint arthroplasty. J Arthroplasty. 1995;10:185-9.

13. Uetsuji S, Kwon AH, Komada H, Okuda Y, Imamura A, Kamiyama Y. Clinical evaluation of closed suction drainage following hepatectomy. Surg Today. 1997;27:298-301. 